\title{
Authors' Reply: Faculty Values
}

\author{
Linda Pololi, MBBS, MRCP ${ }^{7}$, David E. Kern, MD, MPH' ${ }^{2}$, Phyllis Carr, $M D^{3}$, and Peter Conrad, $P h D^{7}$ \\ 'Brandeis University, Waltham, MA, USA; ${ }^{2}$ Johns Hopkins University, Baltimore, MD, USA; ${ }^{3}$ Boston University, Boston, MA, USA.
}

\begin{abstract}
Authors' Reply: Dialogue on values and professionalism in academic medicine is always welcome, and we thank Drs. Poses and Smith, as well as JGIM for this opportunity. The purpose of our hypothesis-generating research study and the article $^{1}$ was to document deeply held values of faculty in the context of understanding the culture of academic medicine ${ }^{2}$. We reported that many faculty are distressed in perceiving that behaviors they witness, and that are rewarded in academic medicine organizations, are not always congruent with their own values. In response to Drs. Poses' and Smith's letter, we definitely did not mean to suggest that faculty should become congruent with their leaders when they (leaders) are out of alignment with the mission of academic medical centers to provide excellence in patient care, education, and research, as well as access to all - including underserved vulnerable populations. The questionable behaviors that some faculty described betray the public trust and the lofty intentions of the great academic medical institutions in this country as expressed in their mission statements. In fact, we checked the mission statements of the index medical schools and were reassured by the similarity of faculty values and the mission statements.

We hope that institutional leaders, through having increased awareness of faculty values and the moral distress among some faculty, will make a more determined effort to re-examine the current rewards system and the perceived institutional tolerance of unprofessional or even at times unethical behaviors. By so doing - and thus gaining the trust and fullhearted support of all their faculty - they will be empowered to
\end{abstract}

Published online April 20, 2010 address with even more energy and success the difficult health care issues of our diverse society.

We point out that we report the views of some, not all faculty members, and that faculty may have been referring to their former institutions. We are now analyzing quantitative survey data from representative faculty in 26 US medical schools to help define the frequency of these views among faculty nationally. Preliminary findings from this national C - Change ${ }^{3}$ survey confirm our qualitative findings. For example, about a quarter of faculty believe that the culture of the institution discourages altruism, about half of the faculty perceive that their institutions do not value teaching, and a third that their institutions do not reward clinical excellence. Coupled with these perceptions, about a third of faculty have seriously considered leaving academic medicine in the prior year. ${ }^{4}$

Linda Pololi, MBBS, MRCP, Brandeis University, Waltham, MA, USA (e-mail: lpololi@brandeis.edu).

\section{REFERENCES}

1. Pololi L, Kern DE, Carr P, Conrad P, Knight S. The culture of academic medicine: faculty perceptions of the lack of alignment between individual and institutional values. J Gen Intern Med. 2009;24:1289-95.

2. Pololi L, Conrad P, Knight S, Carr P. A study of the relational aspects of the culture of academic medicine. Acad Med. 2009;84:106-14.

3. http://cchange.brandeis.edu. Accessed February 19, 2010

4. Article in preparation

J Gen Intern Med 25(7):647

DOI: $10.1007 / \mathrm{s} 11606-010-1330-0$

(c) Society of General Internal Medicine 2010 